\title{
Autoimmunity to the alpha 3 chain of type IV collagen in glomerulonephritis is triggered by 'autoantigen complementarity'
}

\author{
John Reynolds ${ }^{1,4}$, Gloria A. Preston², Barrak M. Pressler ${ }^{3}$, Peter Hewins ${ }^{2}$, Michael Brown², \\ Aleeza Roth ${ }^{2}$, Elizabeth Alderman², Donna Bunch ${ }^{2}$, J. Charles Jennette ${ }^{2}$, H. Terence \\ Cook $^{1}$, Ronald J. Falk ${ }^{2}$, and Charles D. Pusey ${ }^{1}$ \\ ${ }^{1}$ Renal Section, Department of Medicine, Imperial College London, Hammersmith Campus, \\ London, UK \\ ${ }^{2}$ UNC Kidney Center, Department of Medicine, Division of Nephrology and Hypertension, \\ University of North Carolina at Chapel Hill, Chapel Hill, NC, USA \\ ${ }^{3}$ Department of Pathology and Laboratory Medicine, University of North Carolina at Chapel Hill, \\ Chapel Hill, NC, USA \\ ${ }^{4}$ Institute of Biomedical and Environmental Science and Technology, Department of Life \\ Sciences, University of Bedfordshire, Luton, UK
}

\begin{abstract}
'Autoantigen complementarity' is a theory proposing that the initiator of an autoimmune response is not necessarily the autoantigen or its molecular mimic, but may instead be a peptide that is 'antisense/complementary' to the autoantigen. We investigated whether such complementary proteins play a role in the immunopathogenesis of autoimmune glomerulonephritis. Experimental autoimmune glomerulonephritis, a model of anti-glomerular basement membrane (GBM) disease, can be induced in Wistar Kyoto (WKY) rats by immunization with the a3 chain of type IV collagen. In this study, WKY rats were immunized with a complementary a3 peptide (c-a3-Gly) comprised of amino acids that 'complement' the well characterized epitope on a3(IV)NC1, pCol(24-38). Within 8 weeks post-immunization, these animals developed cresentic glomerulonephritis, similar to $\mathrm{pCol}(24-38)$-immunized rats, while animals immunized with scrambled peptide were normal. Anti-idiotypic antibodies to epitopes from c-a3-Gly-immunized animals were shown to be specific for a 3 protein, binding in a region containing sense $\mathrm{pCol}(24$ 38) sequence. Interestingly, anticomplementary a 3 antibodies were identified in sera from patients with anti-GBM disease, suggesting a role for 'autoantigen complementarity' in immunopathogenesis of the human disease. This work supports the idea that autoimmune
\end{abstract}

(C) 2015 Published by Elsevier Ltd.

Address correspondence to: Dr John Reynolds, Renal Section, Department of Medicine, Imperial College London, Hammersmith Campus, Du Cane Road, London W12 ONN, United Kingdom.

Publisher's Disclaimer: This is a PDF file of an unedited manuscript that has been accepted for publication. As a service to our customers we are providing this early version of the manuscript. The manuscript will undergo copyediting, typesetting, and review of the resulting proof before it is published in its final citable form. Please note that during the production process errors may be discovered which could affect the content, and all legal disclaimers that apply to the journal pertain. 
glomerulonephritis can be initiated through an immune response against a peptide that is antisense or complementary to the autoantigen. The implications of this discovery may be far reaching, and other autoimmune diseases could be due to responses to these once unsuspected 'complementary' antigens.

\section{INTRODUCTION}

As early as 1983, an article was published in the Lancet postulating how viral infections may trigger autoantibodies (1). The hypothesis stated that autoantibodies are primarily antiidiotype antibodies against virally-induced antibodies. This line of thought inferred that the viral protein and the corresponding host protein were 'complementary antigens' at a molecular level, giving rise to a pair of complementary immune responses - an antibody against a viral antigen and an antibody against a complementary host protein.

'Complementarity proteins', as proposed in the late sixties, are defined as a pair of proteins encoded by the same gene - one from sense RNA and the second from antisense RNA - and translated in the same reading frame. As posited by the 'molecular recognition' theory, this pair of proteins possess a natural potential for physically joining due to inherent properties in shape, amino acid sequence, and hydropathy, which confers structurally complementary shapes likened to a key and a keyhole (2-4). These ideas have been supported by others, who propose that disease can be incited by an initial antibody response to an antigen that is 'complementary' to the known autoantigen $(5,6)$.

We previously reported that the sera of patients with anti-neutrophil cytoplasm antibody (ANCA) associated vasculitis contain antibodies reactive with 'complementary' proteinase 3 (cPR3) $(7,8)$. We proposed the theory of 'autoantigen complementarity', stating that immunopathogenesis of disease begins with formation of antibodies against a protein complementary to the autoantigen. This elicits a second antibody response against the idiotope of the primary antibody. The anti-idiotype antibodies, besides binding the idiotope of the primary antibody, consequently react with the 'sense' protein, PR3. Epitope analysis of anti-cPR3 antibodies from patients' sera verified their specificity for cPR3 $(9,10)$. Patients were identified who had a memory $\mathrm{T}$ cell population that responded to cPR3 peptide (11). Bearing in mind that antigen must have been presented to $\mathrm{T}$ cells at some point, MHC DRB1*1501 proteins, linked with increased risk for PR3-ANCA disease, were shown to bind to $\mathrm{CPR} 3$ peptide in an antigen-presenting manner (12).

These observations suggest that exposure to proteins complementary to autoantigens, whether from viral infections or not, can be disease-inciting. This is the first report of experiments designed to address this question. The classic antibody-mediated autoimmune glomerulopathy, Goodpasture's or anti-glomerular basement membrane (GBM) disease $(13,14)$, is ideal for these studies, since the disease-associated epitope has been mapped to guide construction of a defined complementary peptide $(15,16)$ and, importantly, there is an established animal model $(17,18)$. The disease is caused by autoantibodies to a component of the GBM in the non-collagenous domain (NC1) of the a 3 chain of type IV collagen, a3(IV)NC1 (19-21). 
Experimental autoimmune glomerulonephritis (EAG), an animal model of Goodpasture's disease, can be induced in susceptible strains of rats and mice by immunization with solubilized GBM $(17,18,22)$ or with recombinant a3(IV)NC1 (23-25). EAG shares many features with the human disease, in that the renal and lung pathology are very similar (26), and the anti-GBM antibodies show the same specificity for the main target antigen, a3(IV)NC1 (24). Wistar Kyoto (WKY) rats have been shown to be genetically susceptible to crescentic glomerulonephritis (27-30), and when immunized with a3(IV)NC1 develop circulating and deposited anti-GBM antibodies, with focal necrotizing crescentic glomerulonephritis and lung haemorrhage. It has been reported that peptides containing the T cell epitope $\mathrm{pCol}(28-40)$ induce severe glomerulonephritis, suggesting that the autoantibody response to GBM antigens could be induced by a single nephritogenic $\mathrm{T}$ cell epitope, with subsequent intra-molecular epitope spreading (31-33). In addition, we have shown that a B and T cell epitope pCol(24-38) can induce EAG (34) and that nasal administration of $\mathrm{pCol}(24-38)$ can reduce severity of EAG induced by a3(IV)NC1 via mucosal tolerance (35).

Our results indicate that a peptide complementary in sequence to the sense immunodominant peptide in EAG, pCol(24-38), when administered to WKY rats, causes autoimmune glomerulonephritis. Also presented are data showing that patients with anti-GBM disease express antibodies reactive with complementary a3(IV)NC1 peptide, supportive of a role for 'autoantigen complementarity' in at least some cases of the human disease.

\section{RESULTS}

\section{Derivation of $\mathrm{pCol}(24-38)$ complementary peptides}

Peptides complementary to $\mathrm{pCol}(24-38)$, an a3(IV)NC1-derived peptide which induces anti-GBM disease in WKY rats (34), were designed by theoretical 5' to 3' transcription of the non-coding DNA strand into antisense RNA, followed by translation in the a3(IV)NC1 reading frame (2,3) (Fig. 1a). The transcribed antisense RNA sequence includes a 'stop' codon complementary to a serine-encoding thymidine-cytosine-adenosine codon; however, substitution of the adenosine base with thymidine, cytosine, or guanidine replaces the antisense 'stop' with glycine $(\mathrm{G})$ or arginine (R)-encoding codons without altering the sense pCol(24-38) amino acid sequence (Fig. 1b). Both these complementary peptides (c-a3-Gly and c-a3-Arg) were synthesized, as the side chains of these amino acids could potentially result in distinct peptide biochemical properties. A scrambled complementary peptide was also designed by random reordering of the c-a3-Gly sequence, which was confirmed by NCBI BLAST to have little homology to any described microbial or WKY rat sequences. Hydropathic scoring of c-a3-Gly and $\mathrm{pCol}(24-38)$ amino acid residues were opposite each another (Fig. 1c), as predicted for complementary protein pairs (4,36). Immunization of WKY rats with either of these $\mathrm{pCol}(24-38)$-complementary peptide antigens would be predicted by the theory of autoantigen complementarity to result in anti-c-a 3 idiotypic antibodies, followed by production of anti-idiotypic antibodies which are capable of binding to native rat kidney $\mathrm{pCol}(24-38)$ autoantigen, and should result in anti-GBM glomerulonephritis (Fig. 1d). 


\section{Glomerulonephritis in WKY rats immunized with different antigens}

The protocol used for $\mathrm{pCol}(24-38)$, c-a3-Gly, and c-a3-Arg immunization of WKY rats in our experiments at Imperial College London reliably induces anti-GBM disease by week 6 when using a3(IV)NC1 or pCol(24-38) immunogens. As expected, pCol(24-38)immunized rats had marked albuminuria (Fig. 2a) and exhibited signs of systemic illness approximately 6 weeks post initial immunization. Rats immunized with either complementary peptide (c-a3-Gly or c-a3-Arg) had mild proteinuria and hematuria (Multistix dipstick; data not shown) at 6 weeks, but were otherwise healthy. However, we reasoned that anti-idiotypic antibody production and glomerulonephritis could be temporally delayed following complementary peptide immunization, and therefore elected to postpone euthanasia. By 8 weeks post immunization, moderate albuminuria had developed in $50 \%$ of c-a3-Gly immunized rats, so euthanasia of remaining animals was performed. Terminal urine collections from rats in both complementary peptide-immunized groups confirmed increased urine albumin concentration that was more severe in c-a3-Gly rats (Fig. 2b). Histopathologic examination of pCol(24-38) and c-a3-Gly-immunized rat kidneys revealed focal proliferative glomerulonephritis with segmental necrosis and/or crescent formation, although fewer glomeruli were affected and lesions were less severe in the c-a3-Gly group (Fig. 2b, c, d). In contrast, glomerular architecture was unremarkable in c-a3-Arg peptideimmunized rats (Fig. 2b, e). Fluorescent GBM deposits of IgG on the GBM were evident in rats immunized with pCol(24-38) (strong, linear deposits, Fig. 2f) or c-a3-Gly (weak, intermittent deposits, Fig. 2g), but not c-a3-Arg (Fig. 2h). Reduction of disease secondary to substitution of a different single amino acid suggests that complementary sequences capable of initiating a pathologic immune response are highly restricted.

Two additional sets of immunizations were performed - one at the University of North Carolina (assisted by Dr. John Reynolds from Imperial College London), and a third at Imperial College London, using identical reagents. Included as an immunogen in these experiments, we used a scrambled peptide that contained the amino acid composition of ca3-Gly to confirm that disease induction in WKY rats was sequence driven rather than being a non-specific response to some other peptide characteristic. Albuminuria was evident in 24-h urine collections from sense $\mathrm{pCol}(24-38)$-immunized rats $(\mathrm{n}=20)$ by week 4 following immunization, increasing in severity by week 6 (Fig. 3a). Albuminuria also developed in c-a3-Gly-immunized rats $(n=20)$ by week 4 and increased in severity at both week 6 and week 8, but magnitude was less than that seen in pCol(24-38)-immunized rats at every time point (Fig. 3a). In contrast, rats immunized with scrambled c-a3-Gly peptide $(n=20)$ did not develop albuminuria at any time point (Fig. 3a). Histopathologic examination of kidneys confirmed development of glomerulonephritis in pCol(24-38) and c-a3-Glyimmunized rats. By week 6, focal proliferative glomerulonephritis was evident in up to $85 \%$ of glomeruli in $\mathrm{pCol}(24-38)$-immunized rats, with segmental necrosis and crescent formation in up to $45 \%$ of glomeruli, and strong linear deposits of $\operatorname{IgG}$ on the GBM evident by fluorescence microscopy (Fig. 3b, c). By week 8, focal proliferative glomerulonephritis became evident in up to $75 \%$ of glomeruli in c-a3-Gly-immunized rats, with segmental necrosis and crescent formation in up to $20 \%$ of glomeruli, and weak, intermittent GBM deposits of IgG (Fig. 3b, c). In contrast, rats immunized with the scrambled c-a3-Gly 
peptide had persistently normal glomerular architecture at week 8 , without any evident GBM deposits of IgG (Fig. 3b, c).

\section{Characterization of the WKY rat immune responses}

As shown previously (34), anti-a3(IV)NC1 antibodies were detected in sera from pCol(2438) immunized rats. Anti-a3(IV)NC1 antibodies (i.e. anti-idiotypic antibodies expected to develop after immunization with complementary peptide) were also detected in sera from ca3-Gly peptide-immunized rats, but not in sera from scrambled peptide-immunized animals (Fig. 4a). On Western blotting antibodies from pCol(24-38) immunized rats bound to monomer and dimer fractions of recombinant a3(IV)NC1. Antibodies from c-a3-Gly peptide-immunized rats bound primarily to monomer fractions of recombinant a3(IV)NC1, while animals immunized with the scrambled peptide showed no significant binding (Fig. 4b). SDS-PAGE of collagenase-solubilized rat GBM showed a range of hexamer, dimer and monomer bands (Fig. 4c). Western blotting of sera from pCol(24-38) and c-a3-Glyimmunized rats against these GBM fragments resulted in a similar binding pattern, whereas sera from rats immunized with scrambled peptide or adjuvant alone failed to bind (Fig. 4d).

\section{Identification of a specific epitope on recombinant a 3 protein recognized by anti-idiotypic antibodies using mass spectrometry}

MALDI-MS/MS analysis identified two dominant rat $a 3$ epitopes (GFIFTR and

ALEPYVSR) bound by total IgG collected from c-a3-Gly-immunized rat serum (Fig. 5a).

Comparison with the published a3(IV)NC1 bovine crystal structure suggests that these epitopes are located on the protein surface, and overlap with the pCol(24-38) peptidecontaining region (Fig. 5b). These two epitope sequences were synthesized and used to immunopurify anti-idiotypic antibodies from total rat IgG from animals immunized with ca3-Gly (Fig. 5c). The specificity of the affinity purified anti-idiotypic antibodies was demonstrated further by reactivity against purified $\mathrm{NC} 1$ hexamers from rat and bovine $\mathrm{GBM}$ by Western blotting, and to the GBM of normal rat tissue sections in an intermittent pattern by immunohistochemistry (Reynolds et al, unpublished observation).

\section{Detection and isolation of anti-c-a3 peptide-reactive antibodies in patient sera}

We asked if anti-c-a3-reactive antibodies were detectable in patients with anti-GBM disease. Anti-c-a3-reactivity was detected in sera from 47\% (7/15) of anti-GBM disease patients (Fig. 6a). To determine whether this reactivity was due to an antibody population distinct from disease-associated anti-a3(IV)NC1 antibodies, total IgG was first isolated from plasmapheresis fluid, followed by anti-a3(IV)NC1 antibody affinity purification using a bovine collagen column. Three elution fractions from each patient were immunoreactive against a3(IV)NC1 peptide (Fig. 6b). When total IgG, affinity-purified anti-a3(IV)NC1 $\mathrm{IgG}$, and anti-a3(IV)NC1-depleted IgG were tested against c-a3-Gly peptide, immunoreactivity was present in total IgG and was retained following anti-a3(IV)NC1 antibody depletion, confirming that these were in fact two separate antibody populations (Fig. 6c). 


\section{Anti-GBM disease patients have antibodies reactive to recombinant human-c-a3-His protein}

A longer, recombinant, hexahistidine-tagged, human c-a3 (rH-c-a3-His) protein was produced in a human cell line to improve immunodetection by using a post-translationally modified complementary antigen with secondary and tertiary structure, compared with the simpler structure expected in synthetic complementary peptides. Western blot probed with an anti-His antibody showed the multimeric forms of the recombinant protein (Supplementary data in Figure 1a of Appendix). The multimers were similar in size to the multimers derived from solubilisation of native NC1, visible in Fig. 3. Anti-GBM patients' total IgG was capable of binding and immunopurifying 40 and $60 \mathrm{kD} \mathrm{rH-c-a3-His}$ multimers (Supplementary data in Figure 1b of Appendix). Data were reproducible using two separate batches of recombinant protein, one purified using fluid chromatography, and the second using a batch-purification approach (Supplementary data in Figure 1c of Appendix). Reactivity was not the result of a generalized increased reactivity to all antigens, as anti-GBM patients' total IgG failed to bind other antigens tested, including hexahistidinetagged recombinant human PR3.

\section{DISCUSSION}

These findings, spanning both rat and human autoimmune kidney disease, can be incorporated into a pathogenic pathway that pivots on aspects of molecular 'complementarity'. We report a new laboratory model supporting the proof-of-principle that induction of autoimmune disease can follow an initial immune response to a complementary protein, and we provide indirect evidence that molecular 'complementarity' could be responsible for some cases of naturally-occurring anti-GBM disease in humans.

We induced autoantigen-specific antibodies and renal disease in WKY rats by immunization with a peptide 'complementary' in amino acid sequence to a well-described nephritogenic sense peptide. Epitope mapping of these anti-idiotypic, autoantigen-specific antibodies identified putative a3(IV)NC1-specific binding sites which overlap with the known rat and human anti-GBM disease autoantibody epitopes $(16,21,37,38)$. Failure to induce disease following immunization with a scrambled peptide, and demonstration of peptide-specific splenocyte proliferation in rats with autoimmune glomerulonephritis (data not shown), strongly suggest that disease induction is due to an antigen-specific immunologic response rather than a consequence of immune complex deposition. We also demonstrated that a subset of anti-GBM disease patients have anti-idiotypic antibodies specific for complementary a3(IV)NC1 peptides and recombinant complementary a3(IV)NC1 protein, both of which are distinct from the pathogenic anti-a3(IV)NC1 autoantibodies, and which demonstrate idiotypic anti-idiotypic properties.

Antibody deposition within the glomeruli of c-a3-Gly-immunized rats with glomerulonephritis was predominantly intermittent rather than linear, as would have been expected in classic anti-GBM disease. A possible reason for this finding is incorrect selection of glycine or arginine as substitute amino acid residues at the 'stop' codon encoded by the antisense RNA sequence. The 'true' anti-GBM disease-inciting complementary antigen could, if exogenous in origin, have any amino acid present at this site. Alternatively, 
endogenously-derived complementary antigens could be translated from DNA with SNPs or point mutations introduced during replication that then lead to alternative amino acid residues. As demonstrated in studies of $\mathrm{T}$ cell epitope spreading, single amino acid changes in peptide immunogen length may have dramatic effects on induction of disease (33). Truncation of amino terminal amino acids of the immunogenic peptide aborts EAG induction and the presence of asparagine at position 19 of the peptide is critical to disease induction (32). Atypical binding would also be related to the association between susceptibility to anti-GBM disease and certain MHC-II alleles noted in both patients $(39,40)$ and laboratory rodents $(27,30)$. The WKY rat strain used in our experiments is of the WKY/CR, RT1-1 MHC-II haplotype, which is more susceptible to EAG than other WKY haplotypes. Relatively poor presentation of complementary peptides by MHC II variants could result in altered or inefficient affinity maturation of the anti-idiotypic anti-a3(IV)NC1 antibodies, that then fail to bind the GBM in a linear fashion.

Immune responses to peptides are highly variable, and sequence analysis cannot predict whether humoral or cell-mediated (TH1, TH2 or TH17) responses will predominate following immunization. The peripheral T-lymphocyte repertoire in patients with anti-GBM disease is skewed toward a TH1 phenotype, but whether this precedes, and therefore influences, the immune response to a complementary antigen is unknown (41). Freund's adjuvant, used here because of our success with similar immunization protocols in other rodent models of autoantigen complementarity (8), promotes a CD4+ TH1-dominant response to co-administered immunogens (42). Conversely, WKY rats are inherently biased towards CD4+ TH2 responses following immunization $(43,44)$. Although future investigations could substitute TH2-favoring adjuvants such as aluminum salts, or use TH1biased rodent strains, we suspect that it is the overall inflammatory milieu at the time of exposure to a complementary antigen, in a host with some unidentified variant in genotype, which determines the initial autoimmune response and how it matures over time. Perhaps the immune response to a single complementary antigen results in development of antiGBM disease in some patients, as opposed to no appreciable effect, or an alternative glomerular disease, in other patients. This could indirectly explain why the magnitude and/or affinity of anti-c-a-3-Gly antibody responses were variable in our anti-GBM disease patients' sera.

When WKY rats are immunized with microbe-derived peptides similar in amino acid sequence to $\mathrm{pCol}(24-38)$ (but in all cases dissimilar to c-a3-Gly), subtle variations in peptide sequence alter clinical manifestations of disease, and in all cases prevent the induction of anti-GBM antibodies (45). Our data support the primary conclusion drawn by the authors of that study, in that there is clearly inherent complexity in initiation of the antia3(IV)NC1 immunological response. Our successful induction of anti-a3(IV)NC1 antibodies via complementary peptide immunization is therefore perhaps surprising.

The data presented here, demonstrating that autoantigen complementarity could be responsible, in theory, for development of anti-GBM disease beg a larger question. As evidence has now been offered to support this theory in two dissimilar glomerular diseases (i.e. ANCA vasculitis and anti-GBM disease), then it is not a big step to suggest that molecular complementarity might contribute to the pathogenesis of other, non-renal 
autoimmune diseases. Evidence already exists for molecular complementarity in patients with Sjogren's syndrome and systemic lupus erythematosus (SLE) (46); anti-idiotypic antibodies can be detected in patients' sera using peptides complementary to the autoantigen B-cell epitopes (47), and mice immunized with either the B cell epitope peptide or its complement develop antibodies against both immunogens (48).

For all autoimmune diseases, it has long been thought that development of autoantibodies will incite disease. What is now evident is that circulating autoantibodies can exist in ostensibly healthy individuals for months if not years prior to the onset of their autoimmune disease, including SLE $(49,50)$, ANCA vasculitis (51) and anti-GBM disease $(52,53)$. The question that arises is what triggers the crucial event that pushes individuals into disease when they have had years of health with circulating autoantibodies. One proposal is that incitement of disease requires provoking the immune system with a pair of molecularly complementary antigens, consequently giving rise to a pair of complementary immune responses - an antibody to a 'self' antigen and an antibody against the complementary protein counterpart $(5,6)$.

In summary, autoantigen complementarity merits further consideration as we strive to explain what induces autoimmune glomerulonephritis, or provokes disease in an individual after years of health in spite of expressing disease-related autoantibodies. It is conceivable that the titer of these "naturally occurring" autoantibodies is below threshold level, and that exposure to a complementary antigen potentiates the levels of autoantibodies through idiotypy. Regardless of the precise mechanisms involved, we have clearly shown for the first time that immunization with a complementary peptide can induce autoimmune glomerulonephritis in a rodent model, and that anti-complementary peptide antibodies can be detected in some patients with anti-GBM disease. The novelty and therapeutic potential of this research make it important that further work is performed to ascertain whether complementary proteins are important in the pathogenesis of autoimmune disease in general.

\section{METHODS}

\section{Experimental animals}

Male WKY rats, aged 8-10 weeks and weighing 120-150 g, were purchased from Charles River (Margate, Kent, UK) and Harlan Inc. (Indianapolis, IN, USA). All animals were housed in standard conditions and had free access to normal laboratory diet and water. All experimental procedures were conducted in accordance with the UK Animals (Scientific Procedures) Act of 1986 and the USA Animal Welfare Act of 1966.

\section{Production of recombinant rat a3(IV)NC1}

Recombinant rat a3(IV)NC1 was produced from a stably transfected HEK293 cell line, as previously described $(24,54)$. Purification of recombinant rat a3(IV)NC1 from the supernatant was carried out by affinity chromatography using an anti-FLAG M2 affinity column (Sigma-Aldrich Company Ltd, Poole, UK). 


\section{Production of synthetic peptides}

The antisense sequence of the a 3 (IV)NC1 cDNA was determined by translation of accession number NM_031364 in the National Center for Biotechnology Information nucleotide data sequence bank. All peptides were synthesized by the University of North Carolina Microprotein Sequencing and Peptide Synthesis Facility.

\section{Experimental protocol}

Experiment 1-WKY rats were administered a single i.m. injection of sense $\mathrm{pCol}(24-38)$ peptide (n=6), c-a3-Gly peptide (COOH-ESSVTLGCGIRGARF-NH $\left.{ }_{2}\right)(n=6)$, or c-a3-Arg peptide (COOH-ESSVTLGCGIRRARF-NH $\left.{ }_{2}\right)(\mathrm{n}=6)$ at a dose of $500 \mu \mathrm{g} / \mathrm{rat}$, in an equal volume of Freund's complete adjuvant (FCA, Sigma-Aldrich Company Ltd), as previously described (34). Blood was collected by tail artery puncture under light anaesthesia (Isofluorane), and $24 \mathrm{~h}$ urine specimens were obtained by placing animals in metabolic cages. Animals immunized with the sense peptide were killed at week 6 and animals immunized with the c-a3-Gly or c-a3-Arg peptides were killed at week 8.

Experiments 2 and 3-WKY rats were administered a single i.m. injection of sense peptide ( $\mathrm{pCol} 24-38)(\mathrm{n}=16), \mathrm{c}-\mathrm{a} 3$-Gly peptide $(\mathrm{n}=20)$ or scrambled peptide $(\mathrm{n}=20)$ at a dose of $500 \mu \mathrm{g} / \mathrm{rat}$, in an equal volume of FCA (Sigma-Aldrich Company Ltd), or FCA alone $(n=5)$ as a control. Animals immunized with the sense peptide were killed at week 6 and animals immunized with the c-a3-Gly peptide or scrambled peptides were killed at week 8. Groups of WKY rats ( $\mathrm{n}=5)$ were also immunized with recombinant rat a3(IV)NC1 (Rec-a3) as a positive control or FCA alone as a negative control, as previously described (24).

\section{Assessment of renal disease following peptide immunization}

Albuminuria-Urinary albumin concentration was determined by rocket immunoelectrophoresis (Amersham Bioscience UK Limited), as previously described $(18,26)$. Briefly, urine samples were subjected to immunoelectrophoresis at $60 \mathrm{v}$ in an electrophoresis tank containing Barbitone buffer (BDH Laboratory Supplies), pH 9.5, for 6 h, using a $1 \%$ agarose gel (BDH Laboratory Supplies) containing rabbit antisera to rat albumin. Albumin concentration was determined by comparison to rat serum albumin standards run in parallel and expressed in mg per $24 \mathrm{~h}$.

Glomerular abnormalities-Kidney tissue was fixed in $10 \%$ neutral buffered formalin, processed and embedded in paraffin wax for light microscopy by standard techniques (Histopathology Department, South Kensington Campus, Imperial College London or Department of Pathology and Laboratory Medicine, UNC-Chapel Hill, NC). Briefly, $3 \mu \mathrm{m}$ sections were stained with haemotoxylin and eosin (H\&E), and periodic acid-Schiff (PAS). Fifty glomeruli per section were assessed and graded by a 'blinded' observer (HTC or JCJ) as: severe (extensive segmental necrosis/crescent formation), abnormal (segmental necrosis and/or extracapillary proliferation) or normal, and expressed as a percentage of glomeruli examined $(18,26)$. 


\section{Assessment of deposited antibodies after immunization with peptides}

Deposition of IgG on the GBM: Deposits of IgG in the glomeruli were detected by direct immunofluorescence, as previously described $(18,26)$. Tissue was embedded in OCT II embedding medium (Miles Inc, Elkhart, Indiana, USA) on cork discs, snap frozen in isopentane (BDH Laboratory Supplies, Poole, Dorset, UK) pre-cooled in liquid nitrogen, and stored at $-70^{\circ} \mathrm{C}$. Cryostat sections were cut $5 \mu \mathrm{m}$ thick and incubated with fluorescein isothiocyanate (FITC) labelled rabbit anti-rat IgG (Serotec Ltd, Oxford, UK). Degree of immunostaining was graded from 0 to $3+$ by a 'blinded' observer (HTC or JCJ).

\section{Assessment of circulating antibody responses after immunization with peptides}

\section{Capture enzyme-linked immunosorbent assay (ELISA)-Anti-FLAG M2} monoclonal antibody (Sigma-Aldridge Company Ltd) was coated onto ELISA plates (Life Technologies, Paisley, UK) at a concentration of $4 \mu \mathrm{g} / \mathrm{ml}$ in carbonate buffer $\mathrm{pH} 9.6$ and incubated overnight. Plates were then incubated with Rec-a3 $(2 \mu \mathrm{g} / \mathrm{ml})$ in carbonate buffer for 1 hour at $37^{\circ} \mathrm{C}$. After blocking with $3 \%$ bovine serum albumin (BSA) for $1 \mathrm{~h}$ at $37^{\circ} \mathrm{C}$, diluted sera (1:50) were applied for $1 \mathrm{~h}$ at $37^{\circ} \mathrm{C}$. Bound antibody was detected by alkaline phosphatase conjugated goat anti-rat IgG (Sigma-Aldrich Company Ltd), using the substrate p-nitrophenyl phosphate (NPP, Sigma-Aldrich Company Ltd). Absorbency was read at 405 nm using an Anthos Multiskan ELISA plate reader (Lab Tech International, Uckfield, UK), and results calculated as mean optical density for each triplicate sample $(18,26)$.

SDS-PAGE and Western immunoblotting-Samples of purified NC1 domains of glomerular basement membrane (kindly provided by Dr Billy Hudson, Vanderbilt University Medical Center, Nashville, TN), and Rec-a3, were loaded onto a 12.5\% SDS gel and electrophoresed at $50 \mathrm{v}$ for $6 \mathrm{~h}(23,54)$. After transfer onto nitrocellulose paper, blots were incubated with sera from animals immunized with FCA alone (as a negative control), Rec-a3 (as a positive control), sense pCol(24-38), c-a3-Gly peptide or scrambled peptide at a dilution of 1:10. Bound antibody was detected by alkaline phosphatase conjugated sheep anti-rat IgG, (Sigma-Aldrich Company Ltd). Each blot was developed with 5-bromo-4chloro-3-indolyl phosphate/nitroblue tetrazolium (Sigma-Aldrich Company Ltd).

\section{Assessment of anti-idiotypic-antibody epitope specificity}

Total IgG from sera of c-a3-Gly-immunized WKY rats was analyzed for antibodies specific for Rec-a3 (55). Immobilized IgG was incubated with Rec-a3 and then subjected to proteolytic digestion. Resulting bound peptides were identified by MALDI-mass spectrometry and MS/MS. Total IgG from sera of scrambled-peptide immunized rats served as a control.

\section{Anti-GBM patient sera and plasmapheresis samples}

Because of the rarity of anti-GBM disease, samples were acquired from several sources. Twenty serum samples from 19 patients were obtained from the Glomerular Disease Collaborative Network (GDCN) biologic sample repository. Samples were identified using an initial search for a final diagnosis of anti-GBM disease $(n=79)$, and then by eliminating those patients with morphologic diagnoses other than rapidly progressive or proliferative 
glomerulonephritis $(\mathrm{n}=28)$, patients with anti-GBM titers less than $40.0 \mathrm{IU} / \mathrm{L}(\mathrm{n}=3)$, and patients with anti-MPO or anti-PR3 ANCA titers greater than $16.0 \mathrm{IU} / \mathrm{L}(\mathrm{n}=28)$. Additional serum samples were obtained from anti-GBM patients that were diagnosed or evaluated at the UNC-Chapel Hill School of Medicine during the time that the work described here was performed $(\mathrm{n}=6)$, or kindly provided by Dr. Thomas Hellmark, Lund University, Sweden $(n=7)$, or Professor Charles Pusey, Hammersmith Hospital, Imperial College London ( $n=6)$. Epidemiologic data on these patients such as age, gender, or race was not collected, but antiGBM, anti-PR3, and anti-MPO antibody titers were recorded and reported when relevant. Plasmapheresis fluid was available from seven patients who were initially diagnosed and treated at UNC-Chapel Hill. All samples were maintained at $-80^{\circ} \mathrm{C}$ from the time of collection until use. Samples were collected, stored, and accessed following review by the UNC Institutional Review Board (IRB), and informed patient consent was obtained.

Total IgG, a3(IV)NC1-specific, and complementary a3(IV)NC1-specific antibody purification

Total IgG purification and affinity purification of antibodies were performed by FPLC (AKTA FPLC with Frac-950 and Unicorn Software; GE Healthcare). Human plasmapheresis fluid was obtained from the UNC-Chapel Hill apheresis facility following approval by the IRB and informed patient consent. Total IgG was purified by precipitation of total serum proteins with 50\% ammonium sulfate, resuspensded into approximately 20 $\mathrm{mL}$ PBS, and dialyzed into PBS over $72 \mathrm{hrs}$ with three successive dialysate switches.

\section{Human anti-GBM disease assessment for the presence of anti-a3(IV)NC1 antibodies}

Total IgG was isolated from plasmapheresis fluid from two patients with anti-GBM disease followed by purification on a bovine a3(IV)NC1 (generously provided by Dr. Thomas Hellmark) affinity column (HiTrap NHS-activated HP column, Amersham Biosciences) by FPLC (AKTA, GE Biosciences). Total IgG, affinity-purified anti-a3(IV)NC1 antibodies, and flow-through (anti-a3(IV)NC1 depleted IgG) were tested for reactivity against complementary protein by ELISA. EIA/RIA high-binding 96-well plates (Costar) were coated overnight at $4{ }^{\circ} \mathrm{C}$ with antigen $(0.25-5.0 \mathrm{ug} / \mathrm{mL})$ and then blocked for $2 \mathrm{~h}$ in $1 \%$ BSA in PBS at room temperature. Patient sera were diluted 1:50-1:100 in 0.1\% BSA in PBS and incubated for $2 \mathrm{~h}$ at room temperature. Alkaline phosphatase-conjugated secondary antibody was added for $1 \mathrm{~h}$ at room temperature. Optical density (OD) at $405 \mathrm{~nm}$ was measured after substrate addition using a VERSAmax tunable microplate reader (Molecular Devices). Immunoreactivity was defined as an OD above the mean plus two standard deviations of the normal controls.

\section{Recombinant human a3 protein production and purification}

Conditioned medium containing recombinant complementary a3(IV)NC1 from transformed HEK293 cells was collected as follows. For each IP reaction $10 \mathrm{~mL}$ of media was incubated with $3 \mu \mathrm{g} / \mathrm{mL}$ of rabbit-origin anti-hexahistidine antibody, $3 \mu \mathrm{g} / \mathrm{mL}$ rabbit-origin negative control, $50 \mu \mathrm{g} / \mathrm{mL}$ anti-GBM patient $\mathrm{IgG}$, or approximately $2 \mu \mathrm{g} / \mathrm{mL}$ of purified antia3(IV)NC1 antibodies (negative control). Protein-antibody complexes were harvested with $50 \%$ protein A/G slurry, subjected to SDS-PAGE, and transferred to nitrocellulose membranes as previously described. Nitrocellulose blots were probed with antihexahistidine antibody (1:100 dilution) to detect presumptively isolated recombinant 
complementary a3(IV)NC1. Duplicate immunoblots were also probed in parallel with a rabbit-origin anti-collagen IV antibody.

\section{Statistical analysis}

Differences between data were determined by the Mann Whitney U test. ANOVA was used to confirm differences between multiple data.

\section{Supplementary Material}

Refer to Web version on PubMed Central for supplementary material.

\section{ACKNOWLEDGEMENTS}

This work was presented in part at the $45^{\text {th }}$ Annual Meeting of the American Society of Nephrology, San Diego, October 2012. This work was supported by grants from the Hammersmith Hospital Charity Trustees and NIH/ NIDDK PO1-DK58335.

\section{REFERENCES}

1. Plotz PH. Autoantibodies are anti-idiotype antibodies to antiviral antibodies. Lancet. 1983; 2:824826. [PubMed: 6137652]

2. Mekler LB. Specific selective interaction between amino acid groups of polypeptide chains. Biofizika. 1969; 14:581-584. [PubMed: 5396298]

3. Mekler LB. On the specific mutual interaction of amino acid residues of polypeptide chains and amino acid residues with codons. Oncology. 1973; 27:286-288. [PubMed: 4704740]

4. Blalock JE, Smith EM. Hydropathic anti-complementarity of amino acids based on the genetic code. Biochem Biophys Res Commun. 1984; 121:203-207. [PubMed: 6547339]

5. Westall FC, Root-Bernstein RS. An explanation of prevention and suppression of experimental allergic encephalomyelitis. Mol Immunol. 1983; 20:169-177. [PubMed: 6188949]

6. Root-Bernstein RS, Couturier J. Antigenic complementarity in the origins of autoimmunity: a general theory illustrated with a case study of idiopathic thrombocytopenia purpura. Clin Dev Immunol. 2006; 13:49-65. [PubMed: 16603444]

7. Pendergraft WF, Pressler BM, Jennette JC, Falk RJ, Preston GA. Autoantigen complementarity: a new theory implicating complementary proteins as initiators of autoimmune disease. J Mol Med. 2005; 83:12-25. [PubMed: 15592920]

8. Pendergraft WF, Preston GA, Shah RR, Tropsha A, Carter CW, Jennette JC, Falk RJ. Autoimmunity is triggered by cPR-3(105-201), a protein complementary to human autoantigen proteinase-3. Nat Med. 2004; 10:72-79. [PubMed: 14661018]

9. Bautz DJ, Preston GA, Lionaki S, Hewins P, Wolberg AS, Yang JJ, Hogan SL, Chin H, Moll S, Jennette JC, Falk RJ. Antibodies with dual reactivity to plasminogen and complementary PR3 in PR3-ANCA vasculitis. J Am Soc Nephrol. 2008; 19:2421-2429. [PubMed: 18701607]

10. Hewins P, Belmonte F, Jennette JC, Falk RJ, Preston GA. Longitudinal studies of patients with ANCA vasculitis demonstrate concurrent reactivity to complementary PR3 protein segments cPR3m and cPR3C and with no reactivity to cPR3N. Autoimmunity. 2011; 44:98-106. [PubMed: 20712431]

11. Yang J, Bautz DJ, Lionaki S, Hogan SL, Chin H, Tisch RM, Schmitz JL, Pressler BM, Jennette JC, Falk RJ, Preston GA. ANCA patients have T cells responsive to complementary PR-3 antigen. Kidney Int. 2008; 74:1159-1169. [PubMed: 18596726]

12. Cao Y, Schmitz JL, Yang J, Hogan SL, Bunch D, Hu Y, Jennette CE, Berg EA, Arnett FC, Jennette JC, Falk RJ, Preston GA. DRB1*15 allele is a risk factor for PR3-ANCA disease in African Americans. J Am Soc Nephrol. 2011; 22:1161-1167. [PubMed: 21617122] 
13. Salama AD, Levy JB, Lightstone L, Pusey CD. Goodpasture's disease. Lancet. 2001; 358:917920. [PubMed: 11567730]

14. Tarzi RM, Cook HT, Pusey CD. Crescentic glomerulonephritis: new aspects of pathogenesis. Semin Nephrol. 2011; 31:361-368. [PubMed: 21839369]

15. Ryan JJ, Mason PJ, Pusey CD, Turner N. Recombinant alpha-chains of type IV collagen demonstrate that the amino terminal of the Goodpasture autoantigen is crucial for antibody recognition. Clin Exp Immunol. 1998; 113:17-27. [PubMed: 9697978]

16. Netzer KO, Leinonen A, Boutaud A, Borza DB, Todd P, Gunwar S, Langeveld JP, Hudson BG. The Goodpasture autoantigen. Mapping the major conformational epitope(s) of alpha3(IV) collagen to residues 17-31 and 127-141 of the NC1 domain. J Biol Chem. 1999; 274:1126711274. [PubMed: 10196215]

17. Sado Y, Okigaki T, Takamiya H, Seno S. Experimental autoimmune glomerulonephritis with pulmonary haemorrhage in rats. The dose-effect relationship of the nephritogenic antigen from bovine glomerular basement membrane. J Clin Lab Immunol. 1984; 15:199-204. [PubMed: 6527375]

18. Reynolds J, Mavromatidis K, Cashman SJ, Evans DJ, Pusey CD. Experimental autoimmune glomerulonephritis (EAG) induced by homologous and heterologous glomerular basement membrane in two sub-strains of Wistar Kyoto rat. Nephrol Dial Transplant. 1998; 13:44-52. [PubMed: 9481714]

19. Saus J, Wieslander J, Langeveld JP, Quinones S, Hudson BJ. Identification of the Goodpasture antigen as the alpha 3(IV) chain of collagen IV. J Biol Chem. 1988; 263:13374-13380. [PubMed: 3417661]

20. Turner N, Mason PJ, Brown R, Fox M, Povey A, Rees AJ, Pusey CD. Molecular cloning of the human Goodpasture antigen demonstrates it to be the alpha 3 chain of type IV collagen. J Clin Invest. 1992; 89:592-601. [PubMed: 1737849]

21. Pedchenko V, Bondar O, Fogo AB, Vanacore R, Voziyan P, Kitching AR, Wieslander J, Kashtan C, Borza DB, Neilson EG, Wilson CB, Hudson BG. Molecular architecture of the Goodpasture autoantigen in anti-GBM nephritis. N Eng J Med. 2010; 363:343-354.

22. Kalluri R, Danoff TM, Okada H, Neilson EG. Susceptibility to anti-glomerular basement membrane disease and Goodpasture's syndrome is linked to MHC class II genes and the emergence of T cell-mediated immunity in mice. J Clin Invest. 1997; 100:2263-2275. [PubMed: 9410904]

23. Sado Y, Boutaud A, Kagawa M, Naito I, Ninomiya Y, Hudson BG. Induction of anti-GBM nephritis in rats by recombinant a3(IV)NC1 and a4(IV)NC1 of type IV collagen. Kidney Int. 1998; 53:664-671. [PubMed: 9507212]

24. Ryan JJ, Reynolds J, Norgan VA, Pusey CD. Expression and characterization of recombinant rat a3(IV)NC1 and its use in the induction of experimental autoimmune glomerulonephritis. Nephrol Dial Transplant. 2001; 16:253-261. [PubMed: 11158397]

25. Hopfer H, Maron R, Butzmann U, Helmchen U, Weiner HL, Kalluri R. The importance of cellmediated immunity in the course and severity of autoimmune anti-glomerular basement membrane disease in mice. FASEB J. 2003; 17:860-868. [PubMed: 12724345]

26. Reynolds J, Moss J, Duda MA, Smith J, Karkar AM, Macherla V, Shore I, Evans DJ, Woodrow DF, Pusey CD. The evolution of crescentic nephritis and alveolar haemorrhage following induction of autoimmunity to glomerular basement membrane in an experimental model of Goodpasture's disease. J Pathol. 2003; 200:118-129. [PubMed: 12692850]

27. Reynolds J, Cook PR, Ryan JJ, Norsworthy PJ, Glazier AM, Duda MA, Evans DJ, Aitman TJ, Pusey CD. Segregation of experimental autoimmune glomerulonephritis as a complex genetic trait and exclusion of Col4a3 as a candidate gene. Exp Nephrol. 2002; 10:402-407. [PubMed: 12381925]

28. Aitman TJ, Dong R, Vyse TJ, Norsworthy PJ, Johnson MD, Smith J, Mangion J, Roberton-Lowe C, Marshall AJ, Petretto E, Hodges MD, Bhangal G, Patel SG, Sheehan-Rooney K, Duda MA, Cook PR, Evans DJ, Domin J, Flint J, Boyle JJ, Pusey CD, Cook HT. Copy number polymorphism in Fcgr3 predisposes to glomerulonephritis in rats and humans. Nature. 2006; 439:851-855. [PubMed: 16482158] 
29. Behmoaras J, Bhangal G, Smith J, McDonald K, Mutch B, Lai PC, Domin J, Game L, Salama A, Foxwell BM, Pusey CD, Cook HT, Aitman TJ. Jund is a determinant of macrophage activation and is associated with glomerulonephritis susceptibility. Nature Genetics. 2008; 40:553-559. [PubMed: 18443593]

30. Reynolds J, Cook PR, Behmoaras J, Smith J, Bhangal G, Tadros S, Tee J, Salama AD, Evans DJ, Aitman TJ, Cook HT, Pusey CD. Genetic susceptibility to experimental autoimmune glomerulonephritis in the WKY rat. Am J Pathol. 2012; 180:1843-1851. [PubMed: 22445570]

31. Wu J, Borillo J, Glass WF, Hicks J, Ou CN, Lou Y-H. T-cell epitope of a3 chain of type IV collagen induces severe glomerulonephritis. Kidney Int. 2003; 64:1292-1301. [PubMed: 12969147]

32. Bolton WK, Chen L, Hellmark T, Wieslander J, Fox J. Epitope spreading and autoimmune glomerulonephritis in rats induced by a T cell epitope of Goodpasture's antigen. J Am Soc Nephrol. 2005; 16:2657-2666. [PubMed: 16049074]

33. Chen L, Hellmark T, Pedchenko V, Hudson BJ, Pusey CD, Fox JW, Bolton WK. A nephritogenic peptide induces intermolecular epitope spreading on collagen IV in experimental autoimmune glomerulonephritis. J Am Soc Nephrol. 2006; 17:3076-3081. [PubMed: 17005930]

34. Reynolds J, Haxby J, Juggapah JK, Evans DJ, Pusey CD. Identification of a nephritogenic immunodominant B and T cell epitope in experimental autoimmune glomerulonephritis. Clin Exp Immunol. 2008; 155:311-319. [PubMed: 19040602]

35. Reynolds J, Abbott DS, Karegli J, Evans DJ, Pusey CD. Mucosal tolerance induced by an immunodominant peptide from rat a3(IV)NC1 in established experimental autoimmune glomerulonephritis. Am J Pathol. 2009; 174:2202-2210. [PubMed: 19406992]

36. Kyte J, Doolittle RF. A simple method for displaying the hydropathic character of a protein. J Mol Biol. 1982; 157:105-132. [PubMed: 7108955]

37. Hellmark T, Chen L, Ohlsson S, Wieslander J, Bolton WK. Point mutations of single amino acids abolish ability of alpha3 $\mathrm{NC} 1$ domain to elicit experimental autoimmune glomerulonephritis in rats. J Biol Chem. 2003; 278:46516-46522. [PubMed: 12970356]

38. Hellmark T, Segelmark M, Unger C, Burkhardt H, Saus J, Wieslander J. Identification of a clinically relevant immunodominant region of collagen IV in Goodpasture disease. Kidney Int. 1999; 55:936-944. [PubMed: 10027930]

39. Huey B, McCormick K, Capper J, Ratliff C, Colombe BW, Garovoy MR, Wilson CW. Associations of HLA-DR and HLA-DQ types with anti-GBM nephritis by sequence-specific oligonucleotide probe hybridization. Kidney Int. 1993; 44:307-312. [PubMed: 8377374]

40. Fisher M, Pusey CD, Vaughan RW, Rees AJ. Susceptibility to Goodpasture's disease is strongly associated with HLA-DRB1 genes. Kidney Int. 1997; 51:222-229. [PubMed: 8995737]

41. Avramidis N, Victoratos P, Yiangou M, Hadjipetrou-Kourounakis L. Adjuvant regulation of cytokine profile and antibody isotype of immune responses to Mycoplasma agalactiae in mice. Vet Microbiol. 2002; 88:325-338. [PubMed: 12220808]

42. Billiau A, Matthys P. Modes of action of Freund's adjuvants in experimental models of autoimmune diseases. J Leukoc Biol. 2001; 70:849-860. [PubMed: 11739546]

43. Nicolaidou E, Okada Y, Zuo XJ, Toyoda M, Marchevsky A, Matloff J, Jordan SC. Prolongation of skin allograft survival is associated with reduced Th1 cytokine responses in the WKY-->F344 rat model. Transplantation. 1999; 68:1393-1401. [PubMed: 10573081]

44. Stevens DB, Gold DP, Sercarz EE, Moudgil KD. The Wistar Kyoto (RT1(1)) rat is resistant to myelin basic protein-induced experimental autoimmune encephalomyelitis: comparison with the susceptible Lewis (RT1(l)) strain with regard to the MBP-directed CD4+ T cell repertoire and its regulation. J Neuroimmunol. 2002; 126:25-36. [PubMed: 12020954]

45. Arends J, Wu J, Borillo J, Troung L, Zhou C, Vigneswaran N, Lou Y-H. T cell epitope mimicry in antiglomerular basement membrane disease. J Immunol. 2006; 176:1252-1258. [PubMed: 16394016]

46. Routsias JG, Tzioufas AG. B-cell epitopes of the intracellular autoantigens Ro/SSA and La/SSB: tools to study the regulation of the autoimmune response. J Autoimmun. 2010; 35:256-264. [PubMed: 20643529] 
47. Routsias JG, Touloupi E, Dotsika E, Moulia A, Tsikaris V, Sakarellos C, Sakarellos-Daitsiotis M, Moutsopoulos HM, Tzioufas AG. Unmasking the anti-La/SSB response in sera from patients with Sjogren's syndrome by specific blocking of anti-idiotypic antibodies to La/SSB antigenic determinants. Mol Med. 2002; 8:293-303. [PubMed: 12428060]

48. Routsias JG, Dotsika E, Touloupi E, Papamattheou M, Sakarellos C, Sakarellos-Daitsiotis M, Moutsopoulos HM, Tzioufas AG. Idiotype-anti-idiotype circuit in non-autoimmune mice after immunization with the epitope and complementary epitope 289-308aa of La/SSB: implications for the maintenance and perpetuation of the anti-La/SSB response. J Autoimmun. 2003; 21:17-26. [PubMed: 12892732]

49. Kanai Y, Sugimura T. Comparative studies on antibodies to poly(ADP-ribose) in rabbits and patients with systemic lupus erythematosus. Immunology. 1981; 43:101-110. [PubMed: 7251045]

50. Arbuckle MR, McClain MT, Rubertone MV, Scofield RH, Dennis GL, James JA, Harley JB. Development of autoantibodies before the clinical onset of systemic lupus erythematosus. $\mathrm{N}$ Engl $\mathrm{J}$ Med. 2003; 349:1526-1533. [PubMed: 14561795]

51. Cui Z, Zhao MH, Segelmark M, Hellmark T. Natural autoantibodies to myeloperoxidase, proteinase 3 , and the glomerular basement membrane are present in normal individuals. Kidney Int. 2010; 78:590-597. [PubMed: 20592714]

52. Yang R, Cui Z, Hellmark T, Segelmark M, Zhao MH, Wang HY. Natural anti-GBM antibodies from normal human sera recognize alpha3(IV)NC1 restrictively and recognize the same epitopes as anti-GBM antibodies from patients with anti-GBM disease. Clin Immunol. 2007; 124:207-212. [PubMed: 17556023]

53. Olson SW, Arbogast CB, Baker TP, Owshalimpur D, Oliver DK, Abbott KC, Yuan CM. Asymptomatic Autoantibodies Associate with Future Anti-glomerular Basement Membrane Disease. J Am Soc Nephrol. 2011; 22:1946-1952. [PubMed: 21868497]

54. Reynolds J, Prodromidi EI, Juggapah JK, Abbott DS, Holthaus KA, Kalluri R, Pusey CD. Nasal administration of recombinant rat alpha3(IV)NC1 prevents the development of experimental autoimmune glomerulonephritis in the WKY rat. J Am Soc Nephrol. 2005; 16:1350-1359. [PubMed: 15814836]

55. Parker CE, Papac DI, Trojak SK, Tomer KB. Epitope mapping by mass spectrometry: determination of an epitope on HIV-1 IIIB p26 recognized by a monoclonal antibody. J Immunol. 1996; 157:198-206. [PubMed: 8683115] 
A

Human sense $\alpha 3($ IV)NC1

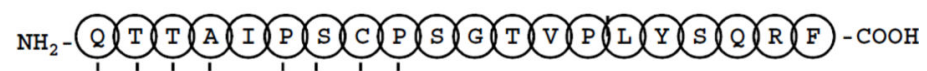

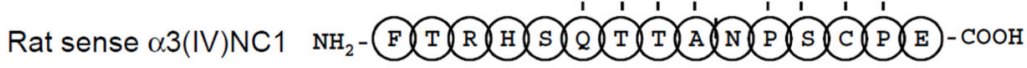

Human c-alpha 3

Human c-alpha 3

(Rat equivalent)

Rat c-alpha 3

Rat scrambled

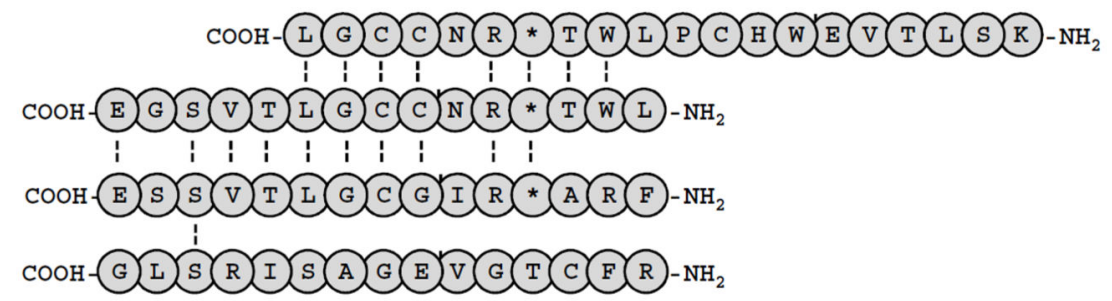

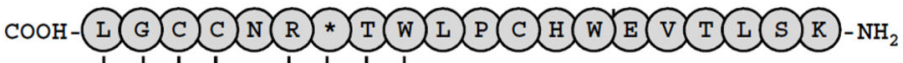

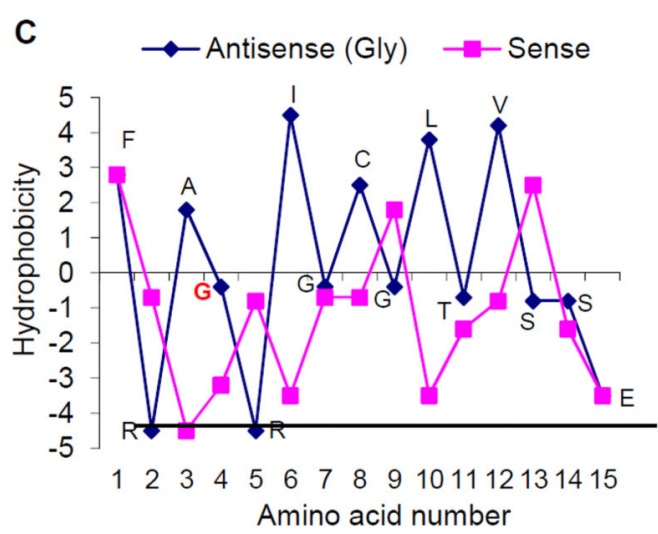

D

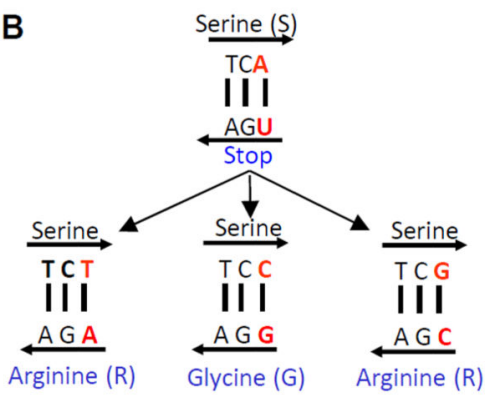

(1) $\mathrm{COOH}$ - ESSVTLGCGIRGARF - $\mathrm{NH}_{2}$ (2) $\mathrm{COOH}-$ ESSVTLGCGIRRARF $-\mathrm{NH}_{2}$

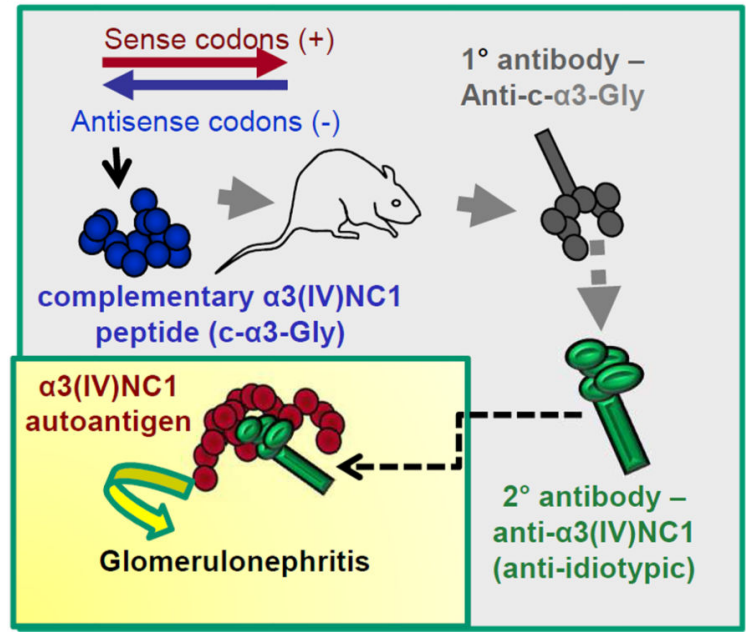

Fig. 1. Complementary peptide derivation and study design

(A) Derivation of 'complementary' peptide to pCol(24-38). Amino acids known to be part of the anti-GBM epitope in human disease are indicated by open circles, and are aligned with the peptide that causes disease in rats. Identical amino acids are shown in alignment with connecting black lines. Complementary peptides are shown with the carboxy terminus to the left such that sense-antisense complementary amino acids are in line with each other. Peptides with amino acid residues denoted with an asterisk $(*)$ were synthesized with either a glycine or arginine at this residue site. (B) Mutation of the third nucleotide in the indicated 
codon preserves the serine residue in the sense strand, but changes the antisense amino acid to either a glycine $(\mathrm{G})$ or arginine $(\mathrm{R})$ residue to produce peptides 1 or 2. (C) By employing the hydropathic scoring system of Kyte and Doolittle, an opposite pattern of hydropathic scores was observed, as is characteristic of amino acids between the complementary peptide pairs. (D) Schematic of working hypothesis: WKY rats immunized with c-a3-Gly peptide will produce primary antibodies against the immunogen. Secondarily produced antiidiotypic antibodies will recognize a3(IV)NC1 protein in the kidney, due to 'complementarity', and cause disease. 

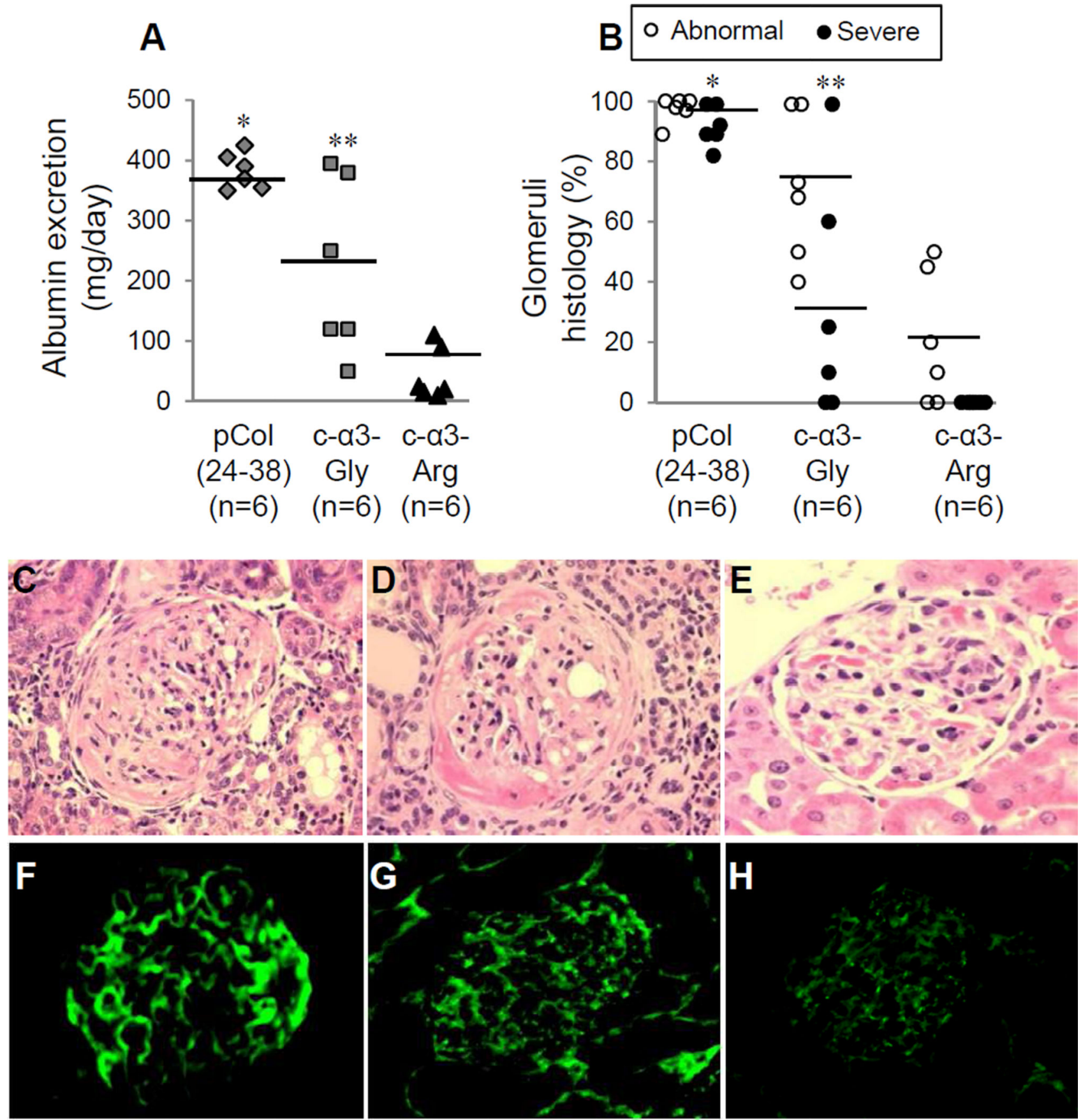

Fig. 2.

Assessment of renal disease in groups of WKY rats $(n=6)$ immunized with sense pCol(2438) peptide, and anti-sense peptides c-a3-Gly and c-a3-Arg. Results shown represent individual animals in each group at week six after immunization for $\mathrm{pCol}(24-38)$ and week eight after immunization for c-a3-Gly and c-a3-Arg. (A) Urine analysis for albumin excretion (*p<0.001; pCol(24-38) versus c-a3-Arg, **p<0.05; c-a3-Gly versus c-a3-Arg). (B) Glomerular abnormalities graded as severe (extensive segmental necrosis/crescent formation), abnormal (segmental necrosis and/or extracapillary proliferation), or normal 
(*p<0.001; $\mathrm{pCol}(24-38)$ versus c-a3-Arg, ${ }^{* *} \mathrm{p}<0.01 ; \mathrm{c}-a 3-G l y$ versus c- $\left.\mathrm{a} 3-\mathrm{Arg}\right) .(\mathbf{C}-\mathbf{E})$ Light microscopy of kidney tissue showing: $(\mathbf{C})$ marked segmental fibrinoid necrosis of the glomerular tuft with crescent formation at week 6 from an animal immunized with pCol(2438); (D) severe crescentic glomerulonephritis with fibrinoid necrosis at week 8 from an animal immunized with c-a-3-Gly; and (E) normal glomerular architecture from an animal immunized with c-a3-Arg. (F-H) Direct immunofluorescence of kidney tissue showing: (F) strong linear deposits of IgG along the GBM at week 6 from an animal immunized with $\mathrm{pCol}(24-38),(\mathbf{G})$ weak, intermittent deposits of $\mathrm{IgG}$ at week 8 from an animal immunized with c-a3-GLY and (H) background fluorescence from an animal immunized with c-a3Arg. Magnification $\times 300$. 

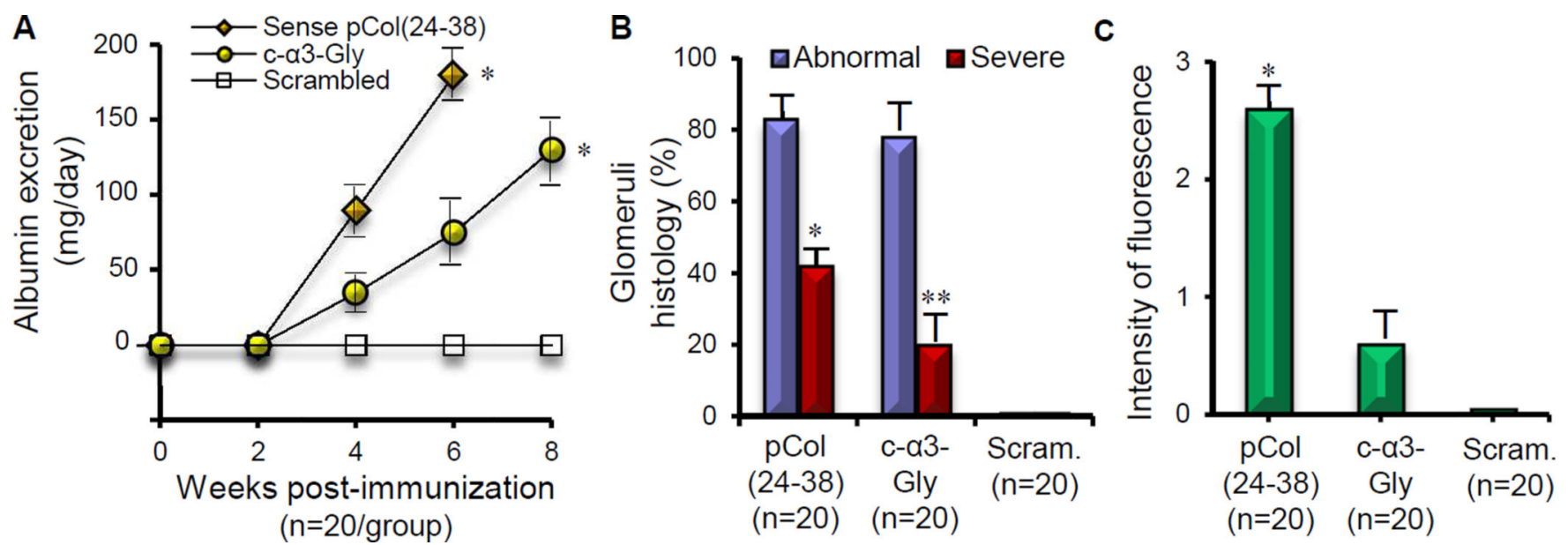

Fig. 3.

Assessment of renal disease in combined groups of WKY rats $(n=20)$ immunized with pCol(24-38) peptide, c-3-Gly peptide and scrambled peptide. Results shown represent the mean \pm SD in each group. (A) albuminuria at different time points after immunization (*p<0.001; $\mathrm{pCol}(24-38)$ versus scrambled, and c- 3-Gly versus scrambled), (B) glomerular abnormalities at week 6 or week 8 after immunization $(* \mathrm{p}<0.005 ; \mathrm{pCol}(24-38)$ versus scrambled, **p<0.05; c- 3-Gly versus scrambled), and (C) deposits of IgG on the GBM at week 6 or week 8 after immunization $(* \mathrm{p}<0.001$; $\mathrm{pCol}(24-38)$ versus scrambled). 

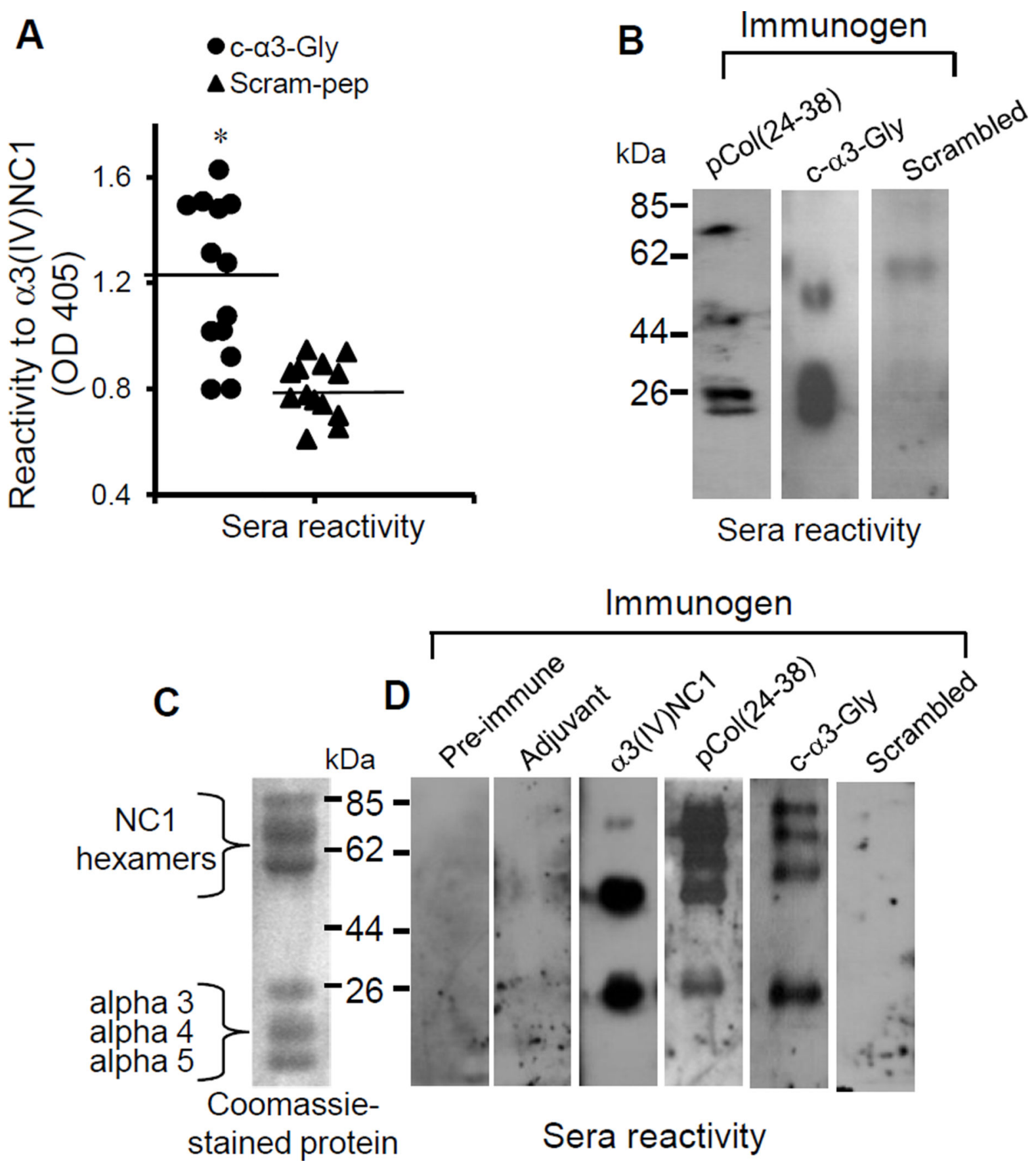

Fig. 4.

WKY rats immunized with c-a3-Gly peptide developed antibodies directed towards a3(IV)NC1. (A) Sera from animals immunized with c-a3-Gly peptide contained circulating antibodies reactive with recombinant a3(IV)NC1 by capture ELISA (*p<0.001; c-a3-Gly versus scrambled). (B) Sera from animals immunized with pCol(24-38) and c-a3-Gly peptide were reactive with recombinant a3(IV)NC1 by Western blotting. (C) Coomassie stained gel of collagenase-solubilised rat glomerular basement membrane (GBM) NC1 collagen IV (kindly provided by Dr. Billy Hudson) showed a range of hexamer, dimer and 
monomer bands. (E) Sera from animals immunized with c-a3-Gly peptide bound to NC1 hexamers and a3 monomers from GBM, similar to that from the sense pCol(24-38) peptide immunized animals. Positive control sera from animals immunized with recombinant rat a3(IV)NC1, and negative control sera from pre-immune animals and from animals given adjuvant alone. 
A

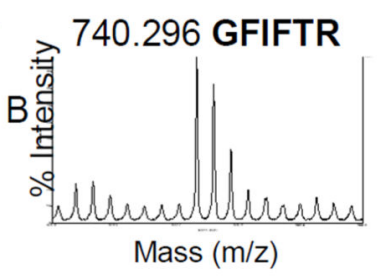

934.357 ALEPYVSR

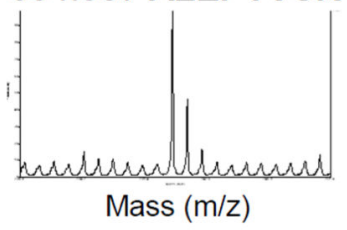

B

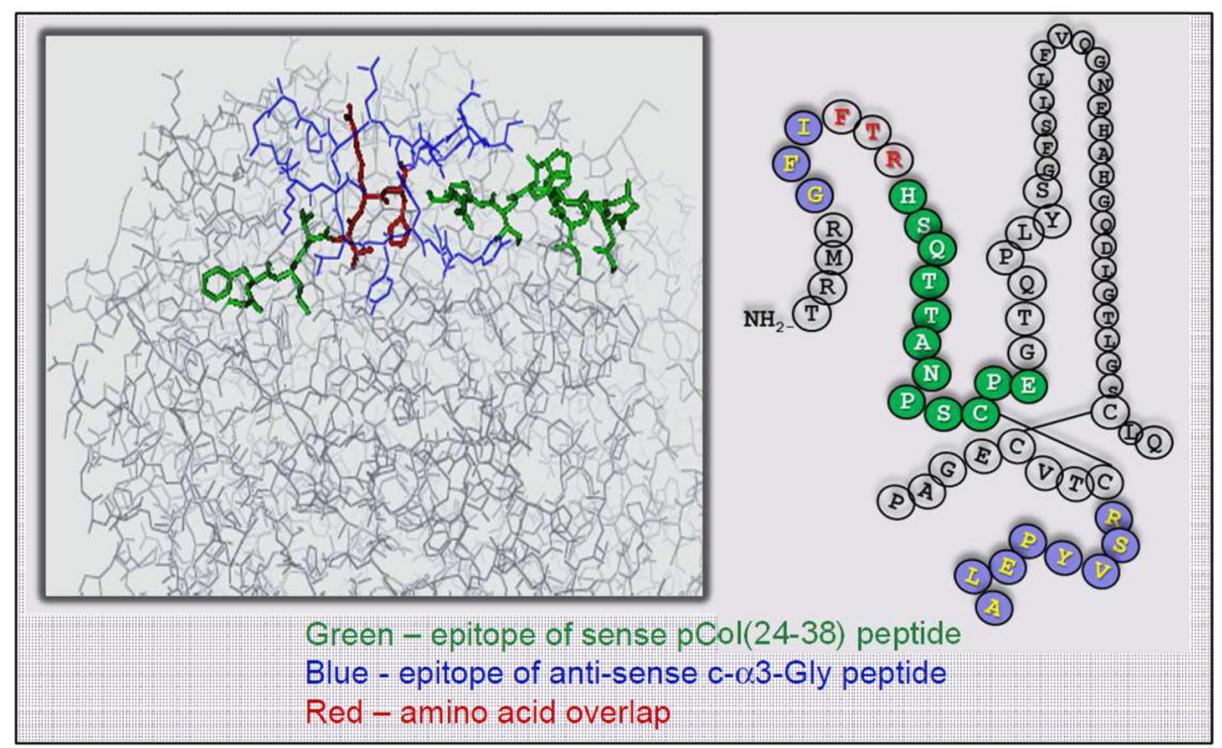

C

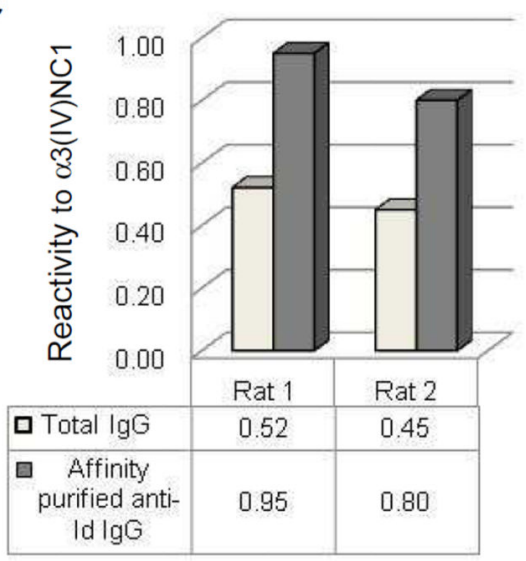

Fig. 5.

Anti-idiotypic antibodies isolated from c-a3-Gly immunized animals were reactive to recombinant a3(IV)NC1. (A) Anti-idiotypic antibody epitope analysis by MS/MS identified two predominant epitopes on recombinant a3(IV)NC1 (GFIFTR and ALEPYVSR). (B) Epitopes of anti-idiotypic antibodies and their proximity to the amino acid sequence of the sense pCol(24-38) peptide (green), anti-sense c-a3-Gly peptide (blue) and amino acid overlap (red) (C) Affinity purified IgG from animals immunized with c-a3-Gly peptide showed enriched reactivity against recombinant $\mathrm{a} 3(\mathrm{IV}) \mathrm{NC1}$ compared to total IgG. 
A

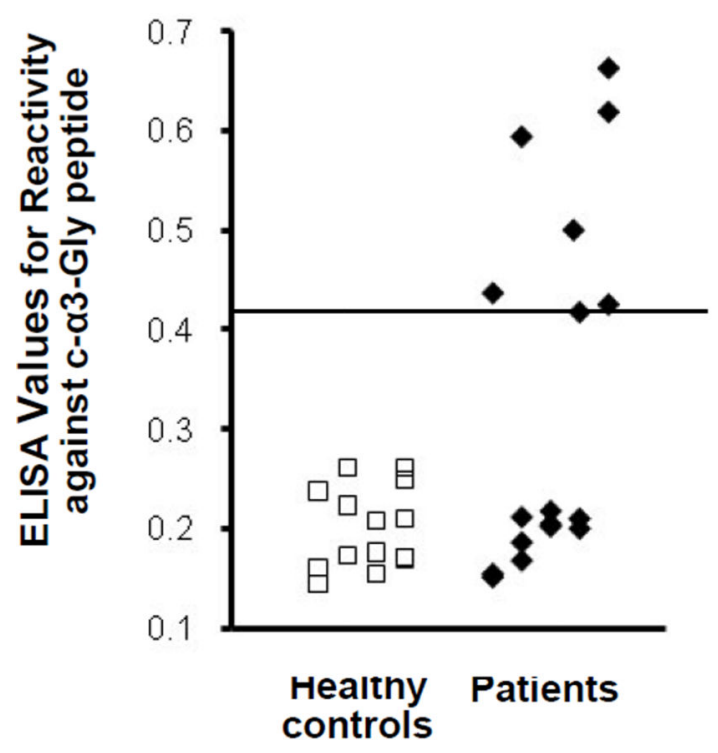

B

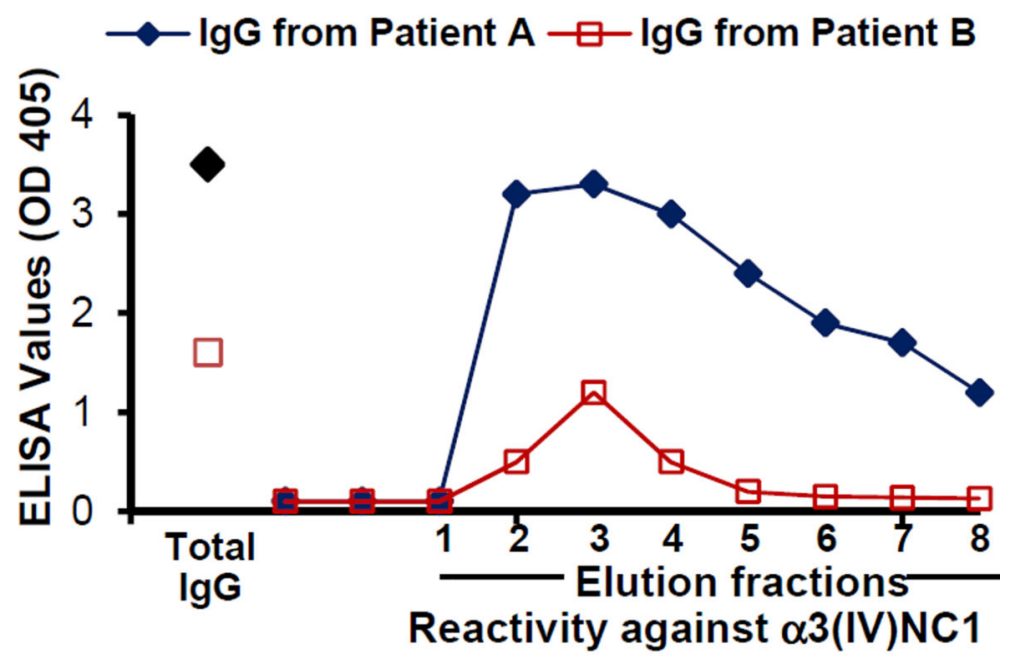

C

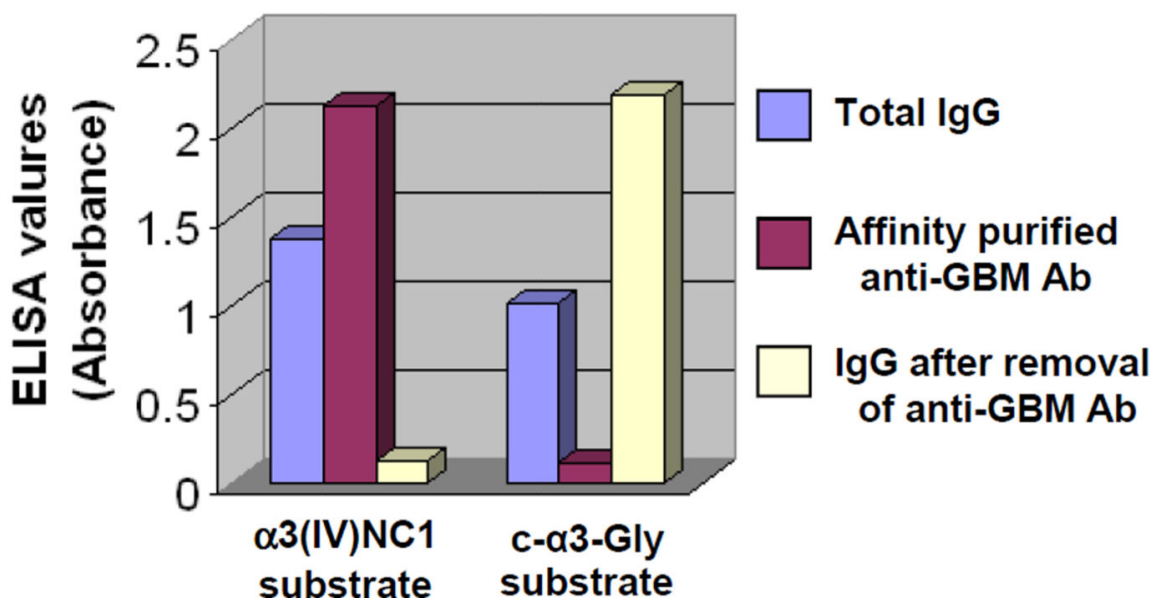

Fig. 6.

Anti-c-a3-Gly antibodies are detectable in a subset of sera from patients with anti-GBM disease. (A) Sera reactivity against human c-a3-Gly peptide by ELISA ( ${ }^{*} \mathrm{p}<0.008$; patients versus healthy controls). (B) Affinity purified IgG from bovine type IV collagen was reactive with a3(IV)NC1. (C) Anti-c-a3-Gly and anti-a3(IV)NC1 immunoreactivity are due to two separate antibody populations. Total IgG, affinity-purified anti-a3(IV)NC1 antibodies, and anti-a3(IV)NC1 depleted IgG were tested for reactivity against c-a3-Gly peptide. Affinity purified anti-a3(IV)NC1 antibodies reacted with a3(IV)NC1, but not c-a3Gly peptide. In comparison, the c-a3-Gly reactivity remained in the $\mathrm{IgG}$ pool depleted of anti-a3(IV)NC1 antibodies. 